\title{
Producción y exportación de melón (Cucumis melo) en Costa Rica
}

Costa Rican melon (Cucumis melo) production and exports

José Eladio Monge-Pérez' 


\section{Palabras clave}

Melón; exportación; producción; Cucumis melo; Costa Rica; Cantaloupe.

\section{Resumen}

Se estudió la producción y exportación de melón en Costa Rica. Se recopiló y analizó información obtenida a través de diferentes fuentes (FAO, BCCR, PROCOMER, MAG, CANAPEMS). Se estableció comunicación personal con gerentes de empresas exportadoras de melón y se revisaron diversas publicaciones sobre el tema. En este artículo se presentan datos sobre el área de siembra, el número de empresas exportadoras, la distribución geográfica del cultivo, el valor de las exportaciones, las exportaciones por país de destino y por tipo de melón a lo largo de varios años. Finalmente, se analizan los desafíos a nivel agronómico, económico, ambiental y logístico para el futuro de la producción de melón en Costa Rica.

\section{Key words}

Melon; exports; production; Cucumis melo; Costa Rica; Cantaloupe.

\begin{abstract}
Melon production and exports from Costa Rica were studied. Information obtained from different sources (FAO, BCCR, PROCOMER, MAG, CANAPEMS) was analyzed. Personal communications were held with managers of melon export companies, and related publications were reviewed. Data about melon planting area, number of trading companies, geographical distribution of farms, value of exports and their volume per country of destiny and by type of melon along several years is presented. Finally, agronomic, economic, environmental and logistic challenges for the future of melon production in Costa Rica are analyzed.
\end{abstract}

\section{Introducción}

El melón, Cucumis melo L., es una planta de la familia Cucurbitaceae, originaria del África tropical. Esta especie es muy apetecida por sus frutos, aunque también se consumen sus semillas, hojas y flores (FAO, 20I2; National Research Council, 2008). La mayor importancia económica se origina en la comercialización de sus frutos.

El melón se cultiva con fines comerciales en Costa Rica desde el siglo pasado. Se sabe que en la década de 1950, el señor Humberto Blanco cultivaba melón en la zona de Barranca, Puntarenas, y lo comercializaba en tiendas exclusivas del San José de esa época (Coto y Blanco, 20l I). También se conoce sobre la siembra de melón a inicios de la década de 1970 en los cantones de Nicoya (Vargas, 20 I2) y Carrillo (Monge, J.E., datos sin publicar).

Las primeras exportaciones de melón a Estados Unidos se realizaron en 1979 y 1980, por medio de la empresa estatal Desarrollo Agroindustrial
(DAISA). En 1986 la empresa privada se incorpora al proyecto de exportación, lo que marca un crecimiento significativo de esta actividad (Díaz y Sandí, 2007; Monge, 1996). Desde 1988, el cultivo del melón ha representado un rubro importante de las exportaciones no tradicionales de Costa Rica, constituyendo uno de los principales productos agrícolas de exportación. La estructura y organización de la cadena del melón en el país fue estudiada en 2004 (Díaz y Sandí, 2007). Sin embargo, no se ha realizado un estudio más detallado sobre el desempeño económico de la actividad.

El objetivo de este trabajo es identificar las principales características económicas de la producción y exportación de melón en Costa Rica.

\section{Materiales y métodos}

Se revisaron los datos de producción y exportación de melón a nivel mundial en el sitio en internet de la Organización de las Naciones Unidas para la 
Alimentación y la Agricultura (FAO) (http://faostat. fao.org). Se revisaron las cifras de exportación de melón de Costa Rica en el sitio en internet de la Promotora de Comercio Exterior de Costa Rica (PROCOMER) (http://www.procomer.com) y se solicitó información adicional al mismo organismo. Asimismo, se solicitó información sobre las exportaciones de melón al Área de Estadísticas de Bienes y Comercio del Banco Central de Costa Rica (BCCR).

También se solicitó información sobre la producción y exportación de melón a la Cámara Nacional de Productores y Exportadores de Melón y Sandía de Costa Rica (CANAPEMS) y el Departamento de Exportaciones del Servicio Fitosanitario del Estado del Ministerio de Agricultura y Ganadería de Costa Rica (MAG). Se solicitó el criterio de varios gerentes de empresas exportadoras de la fruta, con el fin de obtener información relevante sobre el entorno económico y técnico de este cultivo. Se revisó información relevante sobre el tema de la producción y exportación de melón en Costa Rica aparecida en diferentes publicaciones.

Se analizó toda la información recopilada con el fin de dilucidar las principales características económicas de la producción y exportación de melón en Costa Rica.

\section{Resultados y discusión}

\section{Producción, exportación e} importación mundial de melón

En 2010 se cultivaron en el mundo 1,074.558 hectáreas (ha) de melón. La producción en ese año alcanzó 25,0 millones de toneladas métricas (Tm), siendo China el líder indiscutible pues representó el $45 \%$ de la producción mundial (FAO, 20 I 2). En el año 2009 el líder mundial fue Guatemala, con 388,884 Tm, y Costa Rica ocupó el sexto lugar. Sin embargo, en 2007 Costa Rica había ocupado el tercer lugar, por debajo de España y Guatemala (FAO, 20I2).

En cuanto a importación mundial de melón, el líder indiscutible en 2009 fue Estados Unidos, con 65I, I $55 \mathrm{Tm}$ (FAO, 20I2).

\section{Producción y exportación de melón en Costa Rica}

Se considera que el 85\% del melón producido en Costa Rica se dedica a la exportación y el 15\% restante se vende en el mercado interno (Vindas, 2012). En 2011 , el melón fue el quinto producto agrícola de exportación (2,8\% del total), luego del banano (33\%), la piña (30\%), el café oro (16\%) y las plantas ornamentales (3,4\%), generando divisas por un total de US\$66,9 millones (PROCOMER, 20I2).

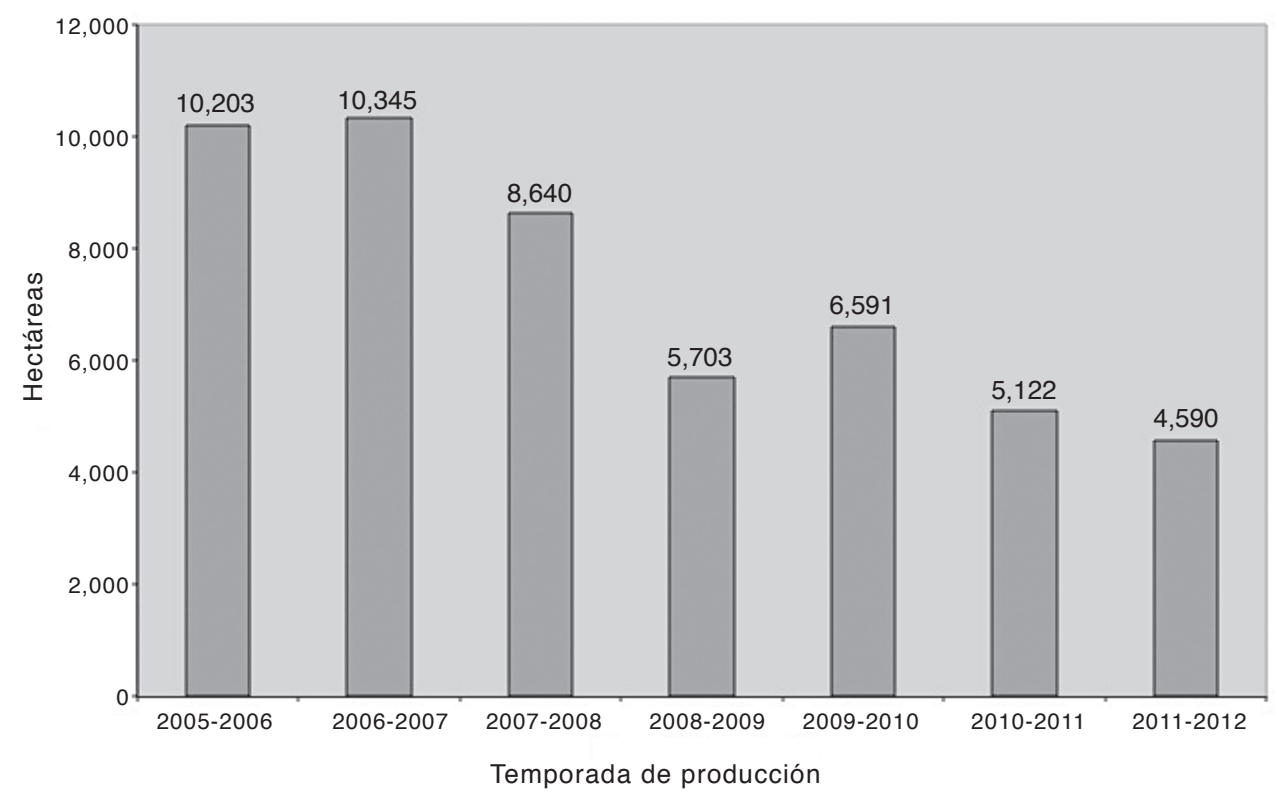

Figura I. Evolución del área de siembra de melón en Costa Rica, en hectáreas, 2006-2012. 


\section{Evolución del área de siembra}

En la figura I se aprecia la evolución del área de siembra de melón desde la temporada 2005-2006 hasta la 20 I I-20 I 2 (normalmente, la temporada de cultivo se inicia en noviembre y finaliza con las últimas cosechas en abril del año siguiente).

A partir de la temporada 2007-2008 se presentó una importante disminución en el área de siembra, pasando de 10,345 ha en la temporada 2006-2007 a solo 4,590 ha 2011-2012, para una disminución del 56\% (CANAPEMS, 2009, MAG, 20I2). Esta reducción fue resultado del retiro de al menos diez empresas de la actividad exportadora de melón (Barquero, 20 I lb, Cisneros 20l3).

\section{Empresas exportadoras y generación de empleo}

El número de empresas exportadoras de melón y/o sandía en Costa Rica (solo se dispone de datos para ambos cultivos juntos) ha mostrado cambios importantes en los últimos años (figura 2).

De 200I a 2003 se incorporaron ocho nuevas empresas a la exportación de estos cultivos, para alcanzar la cifra récord de 30 empresas en 2003. A partir de ese año se han dado fluctuaciones importantes hasta alcanzar 22 empresas en 2011 (CANAPEMS, 20I I; PROCOMER, 20I2). Así, entre
2007 y 201 I, el número de empresas exportadoras de melón y/o sandía se redujo en un $24 \%$.

Se estima que las necesidades de mano de obra en esta actividad son de 1,5 empleados por hectárea (CANAPEMS, 2009; Céspedes, 2008). Por lo tanto, se deduce que en la temporada 20 I I-20 I la exportación de melón generó alrededor de 6,885 empleos directos (MAG, 20 I2); sin embargo, dada la reducción en el área de siembra entre 2005 y 2012 (figura I) se estima que en dicho período se perdieron unos 8,409 empleos en esta actividad.

La exportación de melón representa una importante fuente de empleo en las zonas productoras, aunque hay que destacar que la mayor parte de los trabajadores en este sector son extranjeros, procedentes principalmente de Nicaragua.

\section{Distribución geográfica del cultivo}

En la figura 3 se presenta la distribución geográfica del cultivo de melón para la temporada 20092010, según los cantones de siembra (esta información está disponible solo para esta temporada) (MAG, 20I2).

Destacan los cantones de Carrillo, Liberia y Nandayure, en la provincia de Guanacaste, que juntos representan un 74\% del área. El 59\% del

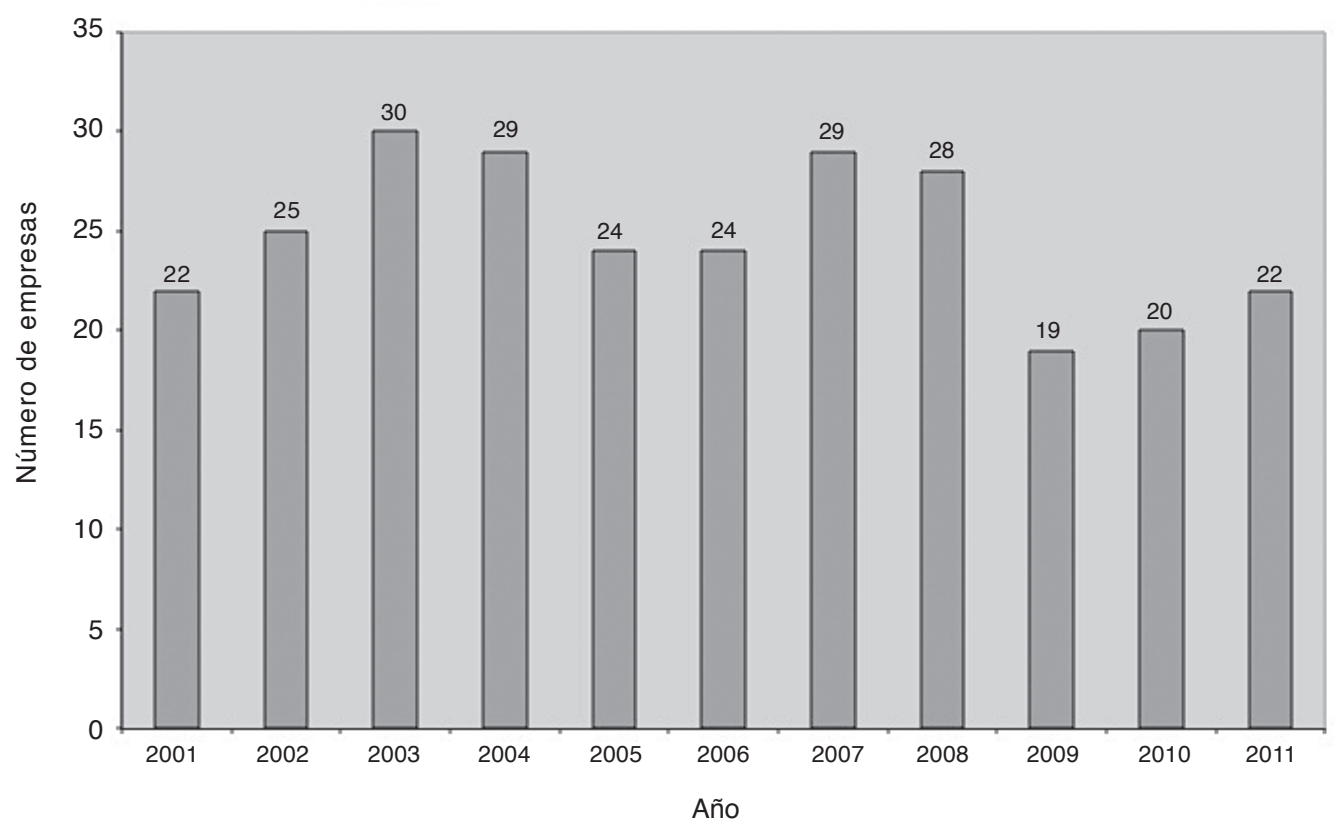

Figura 2. Evolución del número de empresas exportadoras de meñón y/o sandía en Costa Rica, 200 I-20l I.

Fuentes: CANAPEMS, 2011; PROCOMER, 2012. 


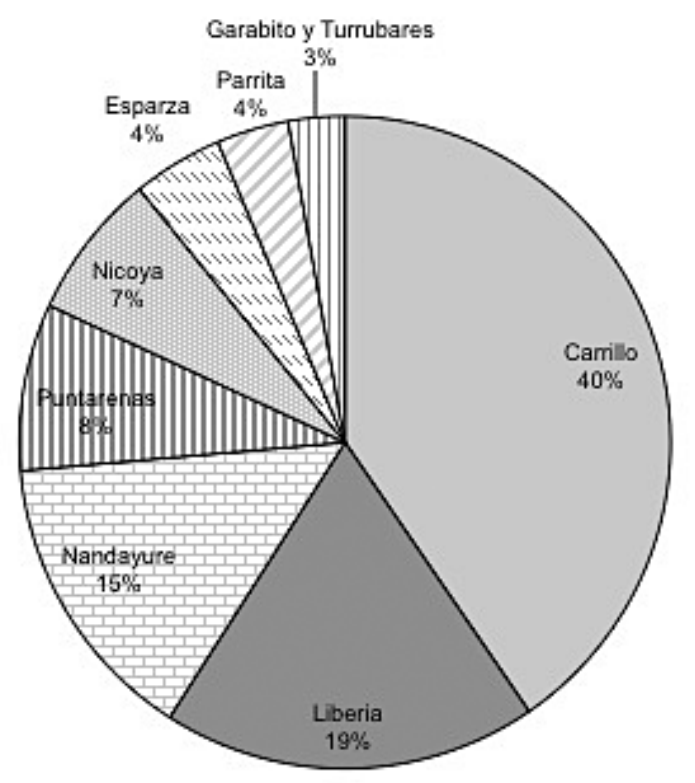

Figura 3. Distribución geográfica del cultivo de melón en Costa Rica, en hectáreas, por cantón, temporada 2009-2010.

Fuente: MAG, 2012.

área corresponde a la zona de la cuenca del río Tempisque, en el sector norte de la provincia de Guanacaste (cantones de Carrillo y Liberia). La segunda área en importancia corresponde al sector de la Península de Nicoya, que concentra el 22\% del área (cantones de Nicoya y Nandayure). Por último, el restante 19\% del área se ubica en la extensa zona del Pacífico Central, que va desde el cantón Central de Puntarenas hasta el cantón de Parrita, incluyendo los cantones de Esparza, Garabito y Turrubares. Sin embargo, desde mediados de 2010 se ha producido una reducción importante en el área de siembra, especialmente en los cantones de Carrillo, Parrita y Central de Puntarenas (zona de Chomes) (Barquero, 20 I0, Villalobos, 20 I0).

\section{Evolución del valor de las exportaciones de melón}

En la figura 4 se presenta la evolución del valor de las exportaciones de melón de Costa Rica desde 1984 hasta 20II (BCCR, 2012, Monge y Ponchner, 1994, PROCOMER, 2012, Soto, 1989).

Se nota una primera etapa de exportaciones modestas (1984-1988), que luego da paso a una fase de rápido crecimiento (1989-1999), seguida de una etapa de contracción (1999-2002), para

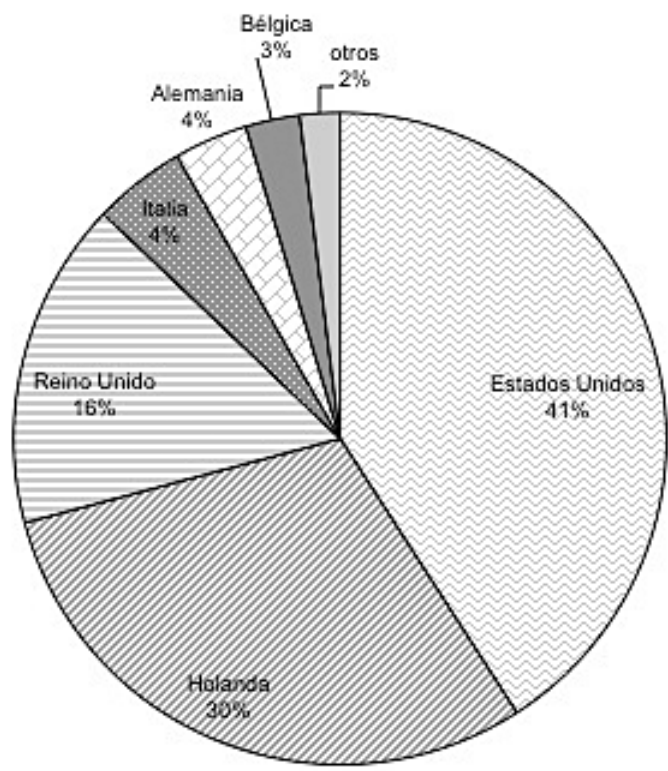

Figura 4. Distribución de las exportaciones de melón de Costa Rica, en dólares, por país de destino, 2011.

Fuente: PROCOMER, 2012.

retomar nuevamente un crecimiento importante (2002-2006). A partir de 2007 se presenta una reducción en el valor de las exportaciones, hasta alcanzar en 201 I los US\$66,9 millones. Esto significa una reducción del valor de las exportaciones de melón de un $21 \%$ entre 2006 y 2011 .

La caída en el valor de las exportaciones de melón observada en los años 2002, 2008 y 20 I I se explica principalmente por lo siguiente:

l. En 2002 se presentó la infección de los cultivos de melón y sandía por la bacteria Acidovorax avenae subsp. citrulli, llegando a afectar severamente unas 1,667 ha (19,2\% del área total), las cuales debieron ser erradicadas como medida de combate (Mora-Umaña y Araya, 2002). Esta infección fue provocada por la venta de semilla contaminada por parte de una empresa productora de semillas, lo cual se conjugó con la presencia de lluvias en los meses de cultivo, lo que provocó un ambiente muy favorable para el desarrollo de la enfermedad (Monge J.E., datos sin publicar). Otra razón es que en ese año el precio promedio del melón cayó a solo 0,29 dólares $/ \mathrm{kg}$, el nivel más bajo entre |99| y 20I I (BCCR, 20 I2). 
2. En 2008 se presentaron varios factores adversos como: a) lluvias importantes durante la época de siembra (cambio climático) lo que favoreció la presencia de plagas (áfidos, mosca blanca) y enfermedades (virus, mildiú velloso, Fusarium solani, Sclerotium rolfsii); b) aumento en el precio de la mayoría de los insumos agrícolas (fertilizantes, plaguicidas, combustibles) provocado por el aumento en el precio del petróleo (Vindas, 2012; Cisneros, 20I3); c) escasez de mano de obra debido al auge inmobiliario (Cisneros, 20/3); d) escasez de contenedores refrigerados; e) escasez de barcos para el transporte del producto; y f) aumento en la competencia por parte de otros países como Guatemala y Honduras, que tienen menores costos de producción (Barquero, 2008; Camacho, 2009; Monge J.E., datos sin publicar, Radio La Primerísima, 2009). Además en ese año se presentó el cierre del mercado estadounidense al melón producido en Honduras debido a la presencia de la bacteria Salmonella spp., lo que afectó también la exportación de melón de Costa Rica por el temor del consumidor a enfermarse (Barquero, 2008). Ese año, una importante empresa nacional, la finca Pelón de la Bajura, dejó de producir melones (unas I,000 ha) tras 21 años de producir y exportar dicha fruta, lo que provocó el despido de 3.000 trabajadores (La República, 2008; Monge J.E., datos sin publicar).

Sin embargo, en 2009 se presentó un repunte en las exportaciones de melón, provocada entre otros factores por la siembra de una nueva variedad (el híbrido de melón tipo Harper llamado Caribbean Gold F-I, que presenta una mayor tolerancia a ciertas enfermedades, el cual sustituyó casi en su totalidad al melón tipo (antaloupe), y por la obtención de mejores precios al reducirse la oferta nacional e internacional producto de la crisis económica mundial iniciada en septiembre de 2008 (Arce, 2009; Monge J.E., datos sin publicar). Otra de las ventajas del melón Harper es que presenta una larga vida de anaquel (maduración lenta), por lo que los costos de cosecha se reducen drásticamente, dado que se deben realizar solo dos o tres ciclos de corta de fruta en el período de cosecha (en el melón Cantaloupe se deben realizar hasta 20 ciclos de corta en dicho período); además, con el melón Harper las pérdidas poscosecha son menores y el manejo poscosecha es más sencillo que en el caso del Cantaloupe.

3. En 20ll se evidenció el efecto de la contracción de la demanda mundial debido a la profundización de la crisis económica, así como los efectos negativos de la revaluación del colón frente al dólar estadounidense, lo que provoca una situación desventajosa para los exportadores costarricenses. En octubre de 2010 la empresa Del Monte anunció el cierre de la operación de su principal finca productora de melón (I,800 ha), ubicada en Filadelfia, Carrillo, Guanacaste, tras 22 años de producir melones en forma ininterrumpida, lo que dejó sin empleo a unas 1,500 personas (Villalobos, 20I0; Monge J.E., datos sin publicar). Pocos días después, Del Monte anunció también el cierre de otras dos fincas ubicadas en Chomes y Parrita, lo que elevó la cifra de empleos perdidos a 2,I25 (Barquero, 2010). También otras empresas dejaron de producir melones durante la temporada 2010-20II en zonas como Parrita y Nandayure (Monge J.E., datos sin publicar). Para la temporada 20II-20I2 se preveía una reducción del 20-25\% en el área de siembra de melón (Vindas, 20I I); sin embargo, dicha caída fue de tan solo el 10\% (figura I).

\section{Exportación de melón, por país de destino}

En la figura 5 se presenta la evolución del número de países de destino de las exportaciones de melón de Costa Rica desde 1998 hasta 201 I. A lo largo de este período el melón nacional se ha exportado a un grupo de entre 11 y 18 países (PROCOMER, 2012).

En la figura 6 se presenta la evolución de la distribución de las exportaciones de melón or país de destino, desde 1998 hasta 201। (PROCOMER, 20 I2).

Es evidente la gran importancia de Estados Unidos como principal mercado de destino en el período 1998-20 I I, a pesar de la gran caída en las exportaciones hacia ese país ocurrida en 2008,2010 y especialmente en 201 I. También es importante destacar la importancia creciente de Holanda como país de destino de las exportaciones de melón a Europa, en contraste con la pérdida en importancia de Bélgica y Alemania (que aparecen en "otros"). Esta situación 


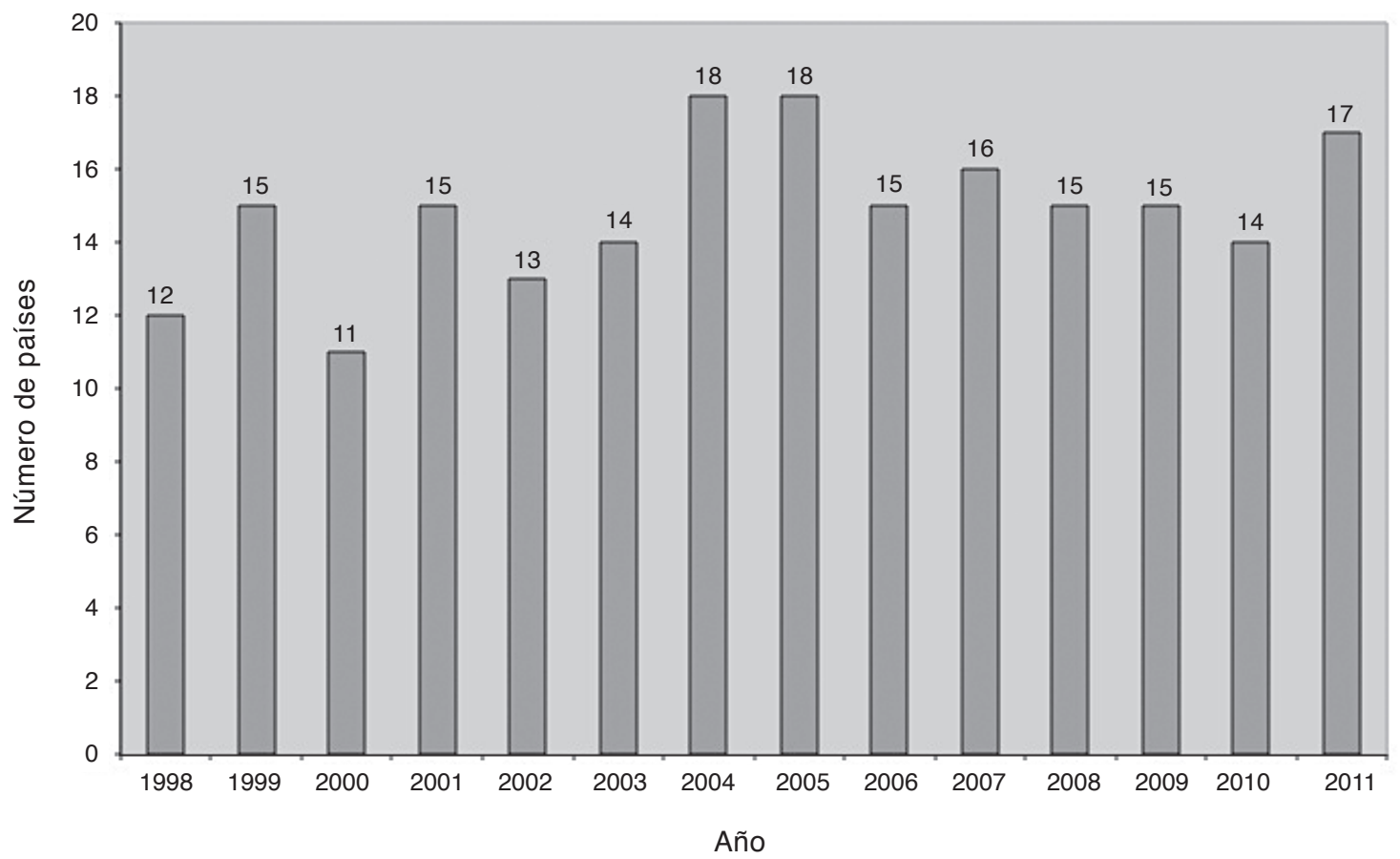

Figura 5. Evolución del número de países de destino de las exportaciones de melón de Costa Rica, 1998-2011. Fuente: PROCOMER, 2012.

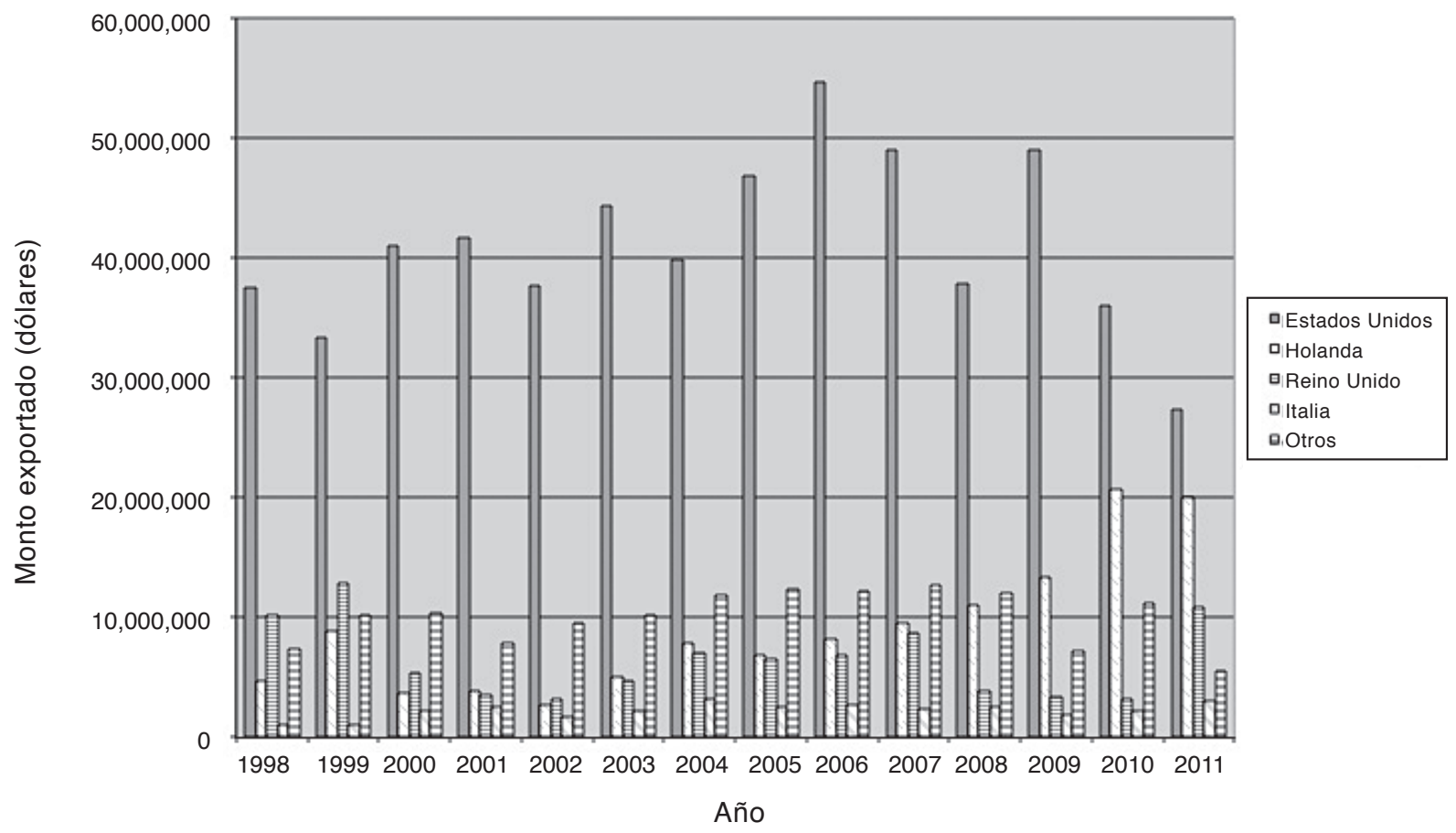

Figura 6. Evolución de la distribución de las exportaciones de melón de Costa Rica, en dólares, por país de destino, 1998-20। I. Fuente: PROCOMER, 2012. 
obedece a factores como tarifas portuarias y localización de las empresas importadoras, entre otros. Sin embargo, el hecho de que los melones ingresen a Europa por Holanda no significa que solo serán vendidos allí, sino que normalmente también son redistribuidos hacia otros países de Europa por vía terrestre.

En 201 I, los principales países de destino del melón exportado desde Costa Rica fueron Estados Unidos (40\%), Holanda (30\%) y Reino Unido (I6\%) (figura 7) (PROCOMER, 20I2).

\section{Tipos de melón, por mercado de destino}

Los principales tipos de melón producidos en Costa Rica para la exportación son: Harper, Cantaloupe, Amarillo, Honey Dew, Galia, Piel de Sapo, Charentais y Orange Flesh. En 2009, la mayor parte de las exportaciones a Estados Unidos correspondió a melón Harper/Cantaloupe (ambos tipos juntos, pues no se dispone de datos por separado) con un $85 \%$, seguido de melón Honey Dew (I5\%). En contraste, en ese año las exportaciones a Europa estuvieron lideradas por melón Amarillo (58\%), seguidas por melón Harper/Cantaloupe (39\%) y melón Galia (3\%) (CANAPEMS, 2009). Estos datos confirman los diferentes gustos y preferencias de los consumidores según las tradiciones culturales de cada país.

\section{Evolución de la cantidad de melón exportado, por tipo}

En la figura 8 se presenta la evolución de la cantidad de melón exportado, de 2003 a 201 I, por tipo de melón (CANAPEMS, 2009; MAG, 20I2).

Se aprecia una importante disminución en la cantidad de melón Harper/Cantaloupe exportado, al pasar de 143,28I Tm en 2005 a solo 72,006 Tm en 201 I, para una reducción del 50\% entre esos años. El melón Amarillo bajó de 39,394 Tm en 2004 a 23,925 Tm en 2009, para una reducción del 39\% en ese período, pero luego repuntó hasta alcanzar 50,094 Tm en 2011. Así, entre 2009 y 201 I se presentó un aumento del $109 \%$ en la producción de este tipo de melón. El melón Honey Dew bajó de 29,664 Tm en 2006 a 12,056 Tm en 20 I , para una reducción del $59 \%$ entre esos años. La cantidad exportada de otros tipos de melones cayó a un mínimo en 2009 pero repuntó en 2010 y 201 I.

Según la distribución de la cantidad de melón exportado en la temporada 2010-2011, por tipo de melón, destacan nuevamente el melón Harperl Cantaloupe (51\%), seguido de melón Amarillo (36\%), Honey Dew (9\%) y otros (4\%) (MAG, 20 I2).

\section{Desafíos para el futuro de la producción y exportación de melón en Costa Rica}

Entre los aspectos que se deben abordar para asegurar la sostenibilidad de la actividad exportadora de melón en Costa Rica están los siguientes:

Cambio climático: El melón se desarrolla en forma idónea en condiciones secas. En Costa Rica, la época seca tradicionalmente se ha presentado entre los meses de noviembre a abril en la región del Pacífico Norte y de diciembre a marzo en la región del Pacífico Central, que son las principales zonas productoras de melón para la exportación. Sin embargo, debido al cambio climático, en los últimos años se han presentado precipitaciones importantes en los meses de producción, lo que provoca condiciones muy favorables para el desarrollo de diversas enfermedades.

Esta situación es particularmente importante cuando se presenta el fenómeno de La Niña, y es uno de los elementos que explican el debilitamiento del sector exportador de melón en Costa Rica (Barquero, 20 I la, Cisneros, 20 I3). En este sentido, la búsqueda de materiales genéticos con resistencia o mayor tolerancia a esas enfermedades será de gran ayuda para disminuir el riesgo de la actividad y asegurar la rentabilidad económica.

Compromiso ambiental: El uso del bromuro de metilo debió ser eliminado como práctica de desinfección de suelos, debido al compromiso adquirido por el país al firmar el Protocolo de Montreal. Como alternativas, se ha desarrollado desde hace varios años el uso de metam sodio, la solarización y el control biológico con microorganismos (Trichoderma spp. y Paecilomyces spp., entre otros) (Monge, J.E., datos sin publicar). Es necesario buscar nuevas tecnologías que permitan reducir el impacto negativo de la producción de melón sobre el ambiente. Todos los esfuerzos por implementar estrategias de manejo integrado de plagas y de reducción en el uso de plaguicidas son bienvenidos. Asimismo, el reciclaje del plástico utilizado, la protección de las fuentes de agua, bosques, manglares y fauna silvestre, son actividades que deben ser incorporadas como parte de la cultura organizacional de las empresas. 


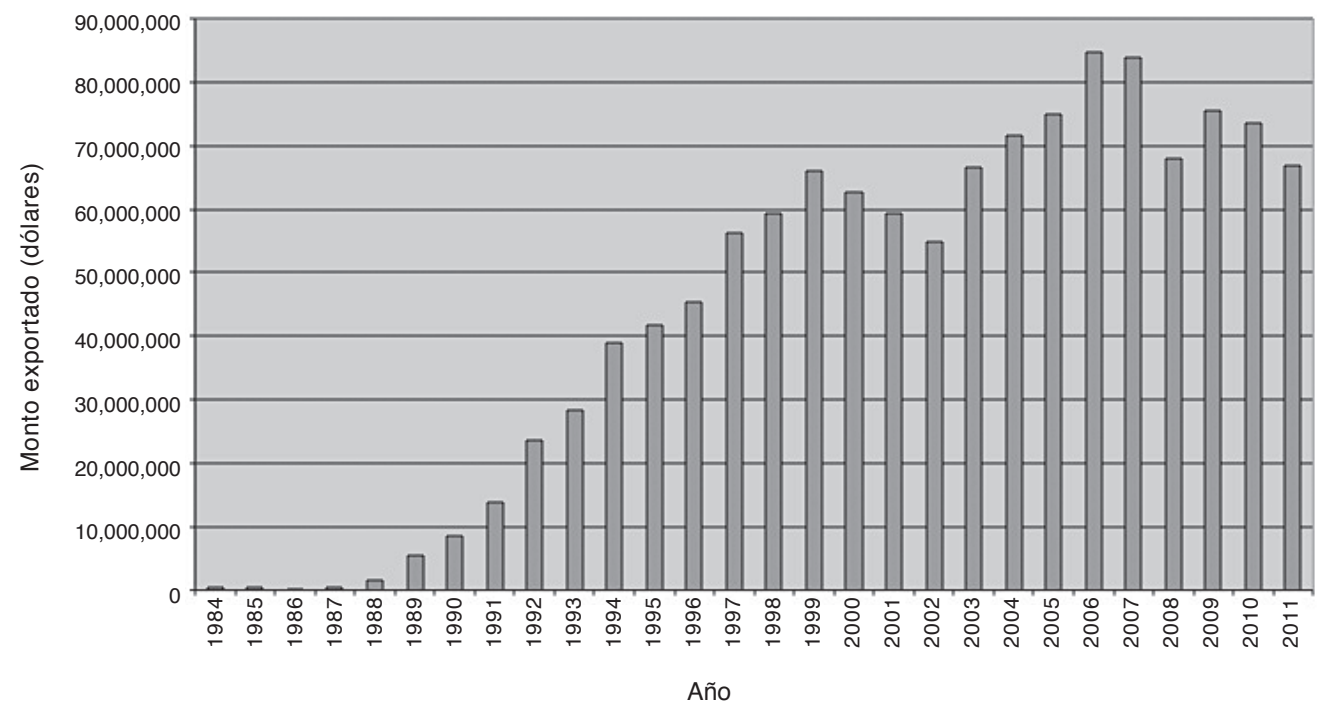

Figura 7. Evolución del valor de las exportaciones de melón de Costa Rica, en dólares, 1984-201 I.

Fuente: BCCR, 2012; Monge y Ponchner, 1994; PROCOMER, 2012; Soto, 1989.

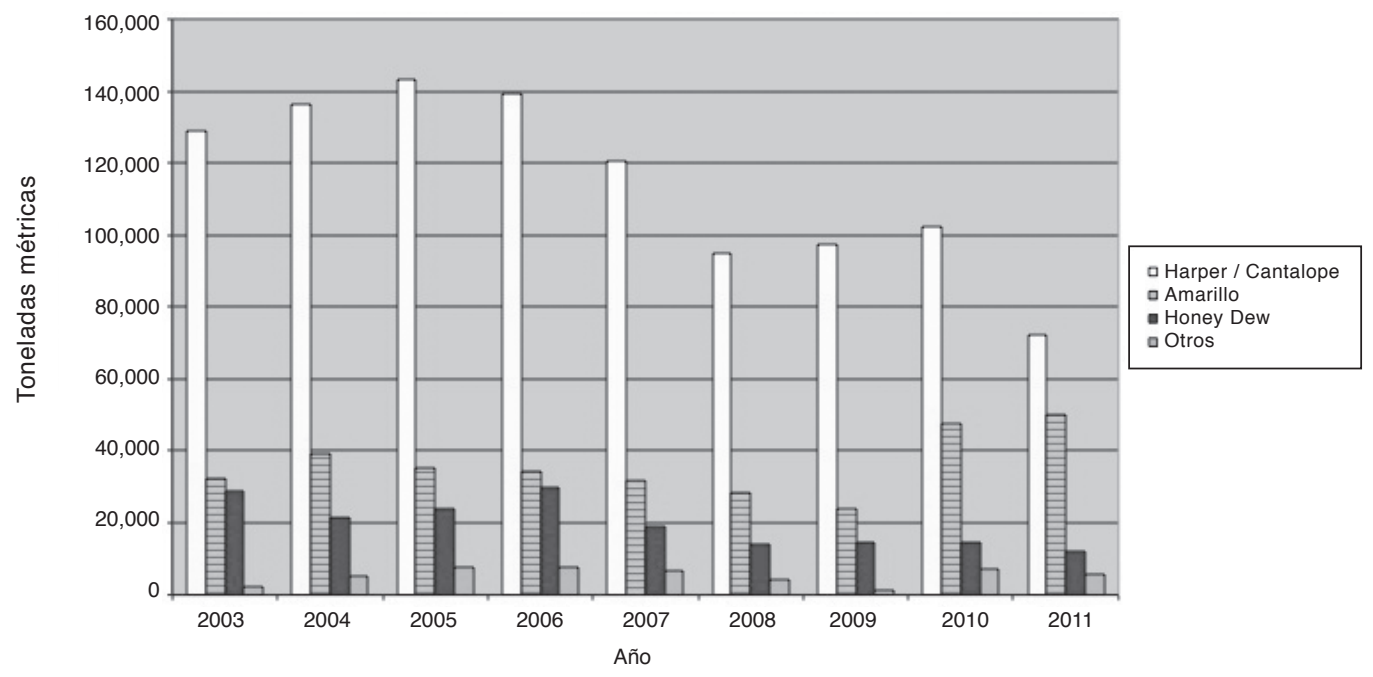

Figura 8. Evolución de la cantidad de melón exportado en Costa Rica, por tipo, en toneladas métricas, 2003-20l I.

Fuentes: CANAPEMS, 2009; MAG, 2012.

Competitividad y disponibilidad de la mano de obra: Costa Rica ha perdido cuota de mercado en la exportación de melón frente a otros países de la región, tales como Guatemala y Honduras, debido a que estos tienen costos de mano de obra más bajos, por la menor cobertura de servicios y seguridad social que ofrecen a sus trabajadores en comparación con Costa Rica (Cisneros, 2013, Vindas, 20II, Vindas, 20I2). Por otra parte, desde hace varios años se presentan problemas con la disponibilidad de mano de obra para esta actividad, la cual debe ser solventada mediante la contratación de población inmigrante, especialmente proveniente de Nicaragua. Este factor es un punto crítico que debe ser manejado mediante una adecuada coordinación con las autoridades respectivas, para garantizar que las fincas cuenten con los trabajadores necesarios para su desempeño.

Capacidad logística: En el pasado reciente Costa Rica ha tenido problemas para exportar melón, debido 
a la insuficiente disponibilidad de contenedores refrigerados en la época de cosecha, donde se compite contra otros productos (como banano, piña y mango) por el espacio en contenedores y barcos. Esta situación fue especialmente problemática en 2006 y 2007, debido a los altos volúmenes de melón exportado. El aumento en la capacidad de carga en los puertos (especialmente los que se ubican en la costa del Caribe) ayudará a solucionar en parte este problema. Las empresas transportistas y navieras también deben ser parte de la solución a esta problemática. A este respecto, los exportadores consideran muy negativo que el costo del transporte del producto desde las fincas hasta los puertos haya aumentado un 60\% entre 2007 y 201 I (Vindas, 20I I).

Innovación: Costa Rica se ha caracterizado por su capacidad de innovación en muchos campos de la producción agrícola. Para mantener y mejorar la competitividad del país en el sector exportador, es necesario promover la innovación en variedades, mercadeo, industrialización y tecnologías de producción. Por ejemplo, en el caso de las variedades, dado que no todos los consumidores aprueban las características organolépticas del híbrido Caribbean Gold F-I (firmeza excesiva de la pulpa, ausencia de aroma), algunas empresas están buscando nuevas opciones en los tipos Cantaloupe o Harper pero con hibridos que presenten mejores características organolépticas. En este sentido, en 2010 una empresa comenzó a producir un nuevo tipo de melón llamado Cantaloupe Amarillo, cuyo nombre comercial es MAG, que es un hibrido de uso exclusivo para ellos en Costa Rica (Monge J.E., datos sin publicar).

Entorno macroeconómico: La crisis económica iniciada en 2008 ha provocado una contracción en el comercio mundial y aún no se vislumbra una recuperación sólida. Los problemas de desempleo y déficit fiscal seguirán siendo importantes en los países importadores de melón por varios años, lo que redunda en una disminución de la demanda de esta fruta. Por otra parte, como consecuencia de la crisis, se ha suscitado una situación cambiaria particular en Costa Rica por la revaluación del colón con respecto al dólar, que está afectando directamente a los exportadores (Cisneros, 2013). Por lo tanto, los exportadores reciben menos colones por dólar, pero dado que una buena parte de sus costos está en colones, se genera un problema de competitividad económica. La empresa Del Monte estimó en 2010 que el costo de producción de melón había aumentado entre $18 \%$ y $22 \%$ como consecuencia de la depreciación del dólar (Barquero, 2010); este panorama fue una de las causas de la reducción en el valor de las exportaciones de melón en la temporada 20l0-20II (figura 4). Esta situación ha llevado a varios productores a cambiar la producción de melón por la producción de arroz o caña de azúcar (Vindas, 20l2).

\section{Conclusiones}

El melón constituye un buen ejemplo de un producto de exportación que surgió al amparo de la política de promoción de exportaciones de productos no tradicionales impulsada en Costa Rica a partir de 1984 (Monge y Ponchner, 1994, Monge, 1996, Díaz y Sandí, 2007), lo que ha resultado en la generación de entre 55 y 85 millones de dólares de divisas por año en los últimos I 5 años (|997-20 I I), y que se ha consolidado como el cuarto o quinto principal producto agrícola de exportación en los últimos años. A pesar de esto, la actividad de exportación de melón no ha estado exenta del efecto negativo de diferentes aspectos macroeconómicos, climáticos, agronómicos y de mercado.

\section{Bibliografía}

Arce, S. (2009). "País ganó más por vender melón, pero sector está cauteloso". La Nación, Costa Rica, 3 noviembre. Obtenido desde: http://wvw.nacion.com/In_ee/2009/ noviembre/03/economia2 I 45577.html.

Barquero, M. (2008). "Cosecha de melón caerá 35\% por lluvia, plagas y mercado". La Nación, Costa Rica, $I^{\circ}$ abril. Obtenido desde: http://wrw.nacion.com/In_ee/2008/abril/0l/economial 480858.html.

Barquero, M. (20I0)." 2. I 25 perderán empleo por cierre de tres meloneras". La Nación, Costa Rica, 12 octubre. Obtenido desde: http://www.nacion.com/2010-10-12/Economia/ NotasSecundarias/Economia2552405.aspx.

Barquero, M. (20IIa). "Agroexportadores presentan graves síntomas de decadencia". La Nación, Costa Rica, 25 abril. Obtenido desde: http://www.nacion.com /2011-04-25/ Economia/NotasSecundarias/Economia2753575.aspx.

Barquero, M. (20। Ib). "Fincas de melón, chayote y plantas quiebran por la crisis". La Nación Costa Rica, 13 mayo, p. 29A. 
BCCR. (2012). Estadísticas sobre exportaciones de melón de Costa Rica. Área de Estadísticas de Bienes y Comercio, Banco Central de Costa Rica, San José. Consulta particular.

Camacho, A.C. (2009). "Exportaciones de melón pierden su jugo; algunas fincas abandonan siembra". El Financiero, Costa Rica, edición 717, 17 mayo. Obtenido desde: http:// www.elfinancierocr.com/ef_archivo/2009/mayo// 7/negocios 1946975.html.

CANAPEMS. (2009). Industria exportadora de melones en Costa Rica. Cámara Nacional de Productores y Exportadores de Melón y Sandía de Costa Rica, San José. Informe interno. 17 de junio. 6 pp.

CANAPEMS. (201 I). San José. Informe interno. 6 pp.

Céspedes, R. (2008). Mapeo de actividades y sectores productivos agropecuarios: Costa Rica. San José: Lara, Segura y Asociados. 485 pp.

Cisneros, M.F. (2013). "En picada cosecha de melón”. La República, Costa Rica, 14 enero. Obtenido desde: http:// www.larepublica.net/app/cms/www/index.php?pk_articulo $=533295315$.

Coto, C. \& Blanco, R. (20I I). Comunicación personal, San José.

Díaz, R. \& Sandí, V. (2007). La cadena de melón en Costa Rica: potencialidades y desafíos internacionales. Revista Centroamericana de Ciencias Sociales 4(2): 69-101.

FAO. (20|2). Food and Agriculture Organization of the United Nations, Roma. Consulta particular. Obtenido desde: http:// faostat.fao.org.

La República. (2008). "Recortan cultivo de melón por incertidumbre de mercado". San José, 21 noviembre. Obtenido desde: http://www.centralamericadata.com/ es/article/ home/Recortan_cultivo_de_melon_por_incertidumbre_ del_mercado.

MAG. (20/2). Departamento de Exportaciones, Servicio Fitosanitario del Estado, Ministerio de Agricultura y Ganadería, San José. Consulta particular.

Monge, A. (1996). Costa Rica, pequeño gran exportador de productos no tradicionales. Ministerio de Comercio Exterior,
San José, 19 pp. Obtenido desde: http://es.scribd.com/ doc/63 I 53057/Costa-Rica-pequeno-gran-exportador-deproductos-no-tradicionales.

Monge, J.E. \& Ponchner, S. (1994). Diagnóstico de la situación y perspectivas económicas de la producción de frutales en Costa Rica. Boletín Técnico Estación Experimental Fabio Baudrit Moreno 27(2): 65- 106.

Mora-Umaña, F. \& Araya, C.M. (2002). Mancha bacteriana del fruto de melón y sandía: manejo integrado de una emergencia. Revista Manejo Integrado de Plagas y Agroecología 66: 105- | 10.

National Research Council. (2008). Lost crops of Africa. Volume III: Fruits. Washington D. C.:The National Academies Press. 354 pp.

PROCOMER. (2012). Estadísticas sobre exportaciones de melón de Costa Rica. Promotora del Comercio Exterior de Costa Rica, San José. Consulta particular. Obtenido desde: http:// www.procomer.com/.

Radio La Primerísima. (2009). "Cultivos de melón en Costa Rica se redujeron 50\% en 3 años". 23 febrero. Managua. Obtenido desde: http://old.rlp.com.ni/noticias/4797।.

Soto, M. (1989). Productos no tradicionales con fines de exportación. En: Resúmenes, VIII Congreso Agronómico Nacional. Volumen III. Colegio de Ingenieros Agrónomos, Cartago, Costa Rica. 3-7 de julio. 198 pp. (pp. 169-179).

Vargas, M.T. (20I2). Comunicación personal. Orotina, Costa Rica.

Villalobos, E. (20/0). "Del Monte cierra finca más grande de melón”. La República, Costa Rica, 8 octubre, p. 9.

Vindas, L. (20I I). "Inestabilidad moverá a una cuarta parte de meloneros hacia otras cosechas en 2012". El Financiero, Costa Rica, 5 junio. Obtenido desde: http://www.elfinancierocr.com/ef_archivo/20 I I/junio/05/negocios2797/ 57. html.

Vindas, L. (20 I2). "El melón está cerca de ser un cultivo para la historia". El Financiero, Costa Rica. 27 septiembre. Obtenido desde: http://www.elfinancierocr.com/economia-y-politica/Costa-Rica-dejara-exportar-melon_0_I58384 I 66. html?print $=$ | 